\title{
Exploration of Teacher Agency in the Implementation of the ESP Language Education Policy in a Chinese University
}

\author{
Shiping Deng \\ Shanghai International Studies University, Shanghai, China
}

\begin{abstract}
This case study investigates language teacher agency in the context of ESP curriculum reform in a Chinese university. Data collected from classroom observations and semi-structured interviews with both teachers and students from five ESP classes are analyzed by conducting a thorough thematic analysis. It is revealed that instead of following the national curriculum and institutional requirements, language teachers as policy arbiters make their own implicit policies which are creating spaces for their own discourses, and in this sense, they are "adjusting" the curriculum policy rather than "implementing" it. Teachers' academic background, their views on the nature of language learning, their profound distrust of the efficacy of ESP courses, and students' explicit performance are the main causes of teachers' actual resistance to the policy. Unlike previous studies of teacher agency, an analysis of students' needs and implicit discourses indicates that teachers' agency excised through their hidden agenda may turn out to be a defense of their unwillingness to change, to the detriment of students' academic performance. This study then suggests that policymakers should notice the negative side of teacher agency and stresses the necessity of a bottom-up survey on teachers' ideologies in the implementation of a language education policy, and argues that creating spaces for negotiating and adjusting the policy at the instructional level, and offering effective teacher education programs are the key to the enactment of the national curriculum.
\end{abstract}

Index Terms - teacher agency, negative side, ideologies, ESP as a language education policy, negotiation, enactment

\section{INTRODUCTION}

College English has received much criticism in China for its incapacity to effectively improve students' English proficiency and deviation from students' practical and occupational needs. There are even studies from the academia that regard the tertiary English education in the past forty years in China as a total failure (Cai, 2017a). The overarching suggestion proposed to optimize the college English curriculum is to switch from general English to English for specific purposes (ESP), which has been experimented and practiced in many universities before the final establishment in the official document - College English Teaching Guidelines published in October, 2020. This paper is therefore to explore the institutional ESP reform at a science and engineering university in China in the context of the national language education policy and reveal how and why language teachers' exerted teacher agency to adjust or resist the national curriculum. Implications for administers and teacher educators to address the teacher agency issue for effective ESP policy enactment are made by conducting a holistic analysis of the challenges in front of the teachers and the hidden discourses of the students.

\section{METHODOLOGY}

To investigate how teacher agency mediates policy change within the context of ESP reform, this research collected data from two sources. Observations were made by the researcher mainly to obtain field data on teachers' actions in policy implementation and students' actual performances; in-depth interviews with teachers and students were conducted to elicit more information about teachers' covert ideologies and students' hidden discourses.

\section{A. Research Setting: the Current National Policy of College English Teaching and the Institutional ESP Reform}

Although College English Teaching Guidelines was just published officially in 2020, there has been an appeal for ESP courses for a long time in The People's Republic of China, from both the academia and the official discourses. Therefore it should be noted that ESP reforms have been initiated in many universities, among which universities featuring science and engineering were those where ESP caused much attention as it is believed that students there need English to be an instrument to enhance the learning of specific disciplines rather than be just part of the general education. The university where this research was conducted belongs to this category. Decision makers there, mainly including the dean of the college of foreign studies, directors of the two departments of college English teaching, have long been discussing how college English can contribute to the development of the university and how the college can maintain its status at a science and engineering university. They reached an agreement by following the ESP reform tide 
and aimed at an integration of language learning and the contents of certain disciplines. Several ESP courses were provided soon afterwards by some English teachers, who had been teaching general English. At the beginning there were no ESP textbooks available, so teachers needed to develop materials by themselves. After about two years, the dean launched a program of editing and publishing ESP textbooks based on the characteristics of the university. ESP courses are defined by decision makers in the university as one part of college English and a bridge between professional English and general English. Before the COVID-19 pandemic, decisions had already been made to develop online ESP courses and several courses were successfully created first as SPOCs and later as MOOCs. The traditional offline courses were shifted into online courses, which fulfilled the urgent needs in the pandemic and later served as important resources of the blended learning that is advocated after class-resumption.

\section{B. Participants}

Participants in this research were recruited by purpose sampling. Five teachers were chosen according to the following criteria: Firstly, they must have been teaching ESP courses for at least 3 years so that they have enough experiences and awareness. Secondly, teachers in administrative positions (who had some power in the decision making process, e.g. as a department director) must be included. As is indicated by (Johnson, 2013, p. 102) compared with people in the same context, actors who hold administrative responsibilities can exert a stronger influence on the creation, interpretation and appropriation of language education policy. Thirdly, each of them must have taught a different ESP course so that the representativeness of the sampling can be ensured.

Among the participants, P5 was one of the two department directors (as is mentioned, there are two departments of college English teaching in the college of foreign studies in the university) when the research was conducted. Others are teachers with no administrative responsibilities. They had been teaching general English for many years, but none of the five teachers had ESP teaching experiences before the reform was initiated. They are addressed by codes created for ethic consideration. The participants' profiles are presented in Table I.

TABLE I.

PARTICIPANTS' INFORMATION

\begin{tabular}{|l|l|l|l|l|l|}
\hline Participants & Gender & Title & $\begin{array}{l}\text { Teaching } \\
\text { experiences }\end{array}$ & $\begin{array}{l}\text { Administrative } \\
\text { responsibilities }\end{array}$ & teaching experiences of ESP \\
\hline P1 & female & $\begin{array}{l}\text { associate } \\
\text { professor }\end{array}$ & 13 years & No & 3 years \\
\hline P2 & female & lecturer & 16 years & No & 4 years \\
\hline P3 & female & $\begin{array}{l}\text { associate } \\
\text { professor }\end{array}$ & 20 years & No & 5 years \\
\hline P4 & female & lecturer & 20 years & No & 4 years \\
\hline P5 & male & lecturer & 16 years & department director & 5 years \\
\hline
\end{tabular}

\section{Data Collection}

To reveal teacher agency in the ESP policy reform, all participants were invited in in-depth interviews in which questions concerning their teaching practice, their interpretation and appropriation of the educational policy, their ideologies of the ESP reform, their evaluations on students' academic performances after the policy change were asked. Every participant was interviewed respectively for about 30 minutes during which teachers were encouraged to share the teaching activities they designed to adjust to the new policy context, give an account of their mentality changes, and make free comments on the policy change according to their understanding of ESP education. With the five participants' permission, the researcher then joined the ESP classes (both online and offline) and observed the interactions in the teaching and learning practice. Students were also invited to share their understandings of the teachers' teaching performances and their self-evaluation on academic progress they made in the ESP classes. Data collected from classroom observation and informal interviews with students were transcribed as field notes.

\section{Data Analysis}

Interview data and field notes are analyzed by conducting thematic analysis. The researcher coded the collected data word by word to identify important themes pertinent to teacher agency. A second round of coding was conducted days later. Themes emerging from the two rounds of coding were compared and treated as complementary resources. The researcher then synthesized all the themes, trying to make a comprehensive "theory". The themes fall into the following groups: (1) teachers' actual reactions to the ESP reform, (2) teachers' implicit discourses on the policy change, (3) teachers' understanding of students' explicit performance in and after the ESP courses, (4) students' real needs and the implicit discourses of their ESP learning outcomes. A further and closer examination of the themes highlighted the causes of teacher agency (in real sense, resistance to the policy change) in the ESP curriculum policy: (1) teachers' academic background, (2) their views on the nature of language learning, (3) their profound distrust of the efficacy of ESP courses, and (4) students' unsatisfactory explicit performance.

\section{RESUltS}




\section{A. Teachers' Overt and Covert Reactions to the Top-down Policy}

Research results show that for ESP teachers there is a dilemma of whether or not to follow the national and institutional discourses and they chose to exercise their agency to adjust the teaching practice based on their understanding of the top-down policies. They overtly were teaching ESP courses by following the principles set by the institutional arbiters, but on the other hand, their covert practice revealed a rather different ideology as the institutional requirements were not met in their teaching. As P3 said:

The ESP syllabus requires us to integrate disciplinary contents into the teaching and learning of English, but I found it hard to do so. I need to make the class manageable so that I can get into my "comfortable zone", which I believe really important for successful teaching. You know, a teacher can never teach well if he or she feels out of place in class. So I found my ESP class as "liangzhangpi" (a Chinese colloquial expression meaning that two related matters or aspects become disjointed and uncoordinated). I mean, I may translate the text literally, but I seldom explain the meaning, which is what I cannot manage. The focus in my ESP class is still the same as that in the general English courses: language skills such as listening, reading, translating, etc., of which reading is what I pay much attention to.

Similar expressions are also found in the interview with other teachers. It seems to be the usual case that teachers would claim their classes as ESP classes overtly but regard the classes another form of general English, in which only the materials in the textbooks are different.

\section{B. Students' Explicit Performance After Taking the ESP Courses and Their Real Needs and Implicit Discourses}

Research results also reveal the inconsistency in students' explicit performances and hidden discourses. Explicitly they showed indifference to what was taught in the ESP classes and it seemed credits were all that they cared. They were not active in class, and some of them even fell asleep. Those who were asked to respond to the teachers often stood still, without giving any valuable remarks or ideas. But interview data from students brought researchers a picture which is rather different from what happened in the classroom. The following excerpt represents most students' hidden ideology:

I really want to learn something in ESP classes, but when I found there is no big difference between ESP and general English classes, I chose to be quiet. I need the credits, so I attended each class, but I knew my performance was not good. Actually, after class I usually searched for similar courses in icourse (a Chinese MOOC platform) for self-study. I really need ESP courses, as I believe they are more useful for my study and my future career.

The seemingly contradictory discourses from the excerpt above prove that ESP reform is a correct decision from the students' perspective. If the agency exerted by teachers is aimed at enacting the real ESP curriculum, it is conducive; otherwise, if the agency changes the direction of the national and institutional direction and deviates from students' expectations and needs, then it has to be considered as negative. What should be made clear is that teacher agency should be analyzed and evaluated based on a thorough and rigorous consideration and investigation of students' real needs.

\section{The Causes of Teacher Agency in the ESP Curriculum Policy}

\section{Teachers' academic background}

This section reveals that teachers' academic background, as an important part of one's life experience, has a notably effect on their responses to the policy change in the context of ESP reform. This confirms Kayi-Aydar's finding that agency is constructed by individual's life experience (Kayi-Aydar, 2015). However, it shows that academic background confines teachers' vision and is one of the major stumbling blocks to any positive attempt to make some change. P1 insisted that as a teacher, she has the freedom of interpreting the policy in her own way:

As a language teacher, I cannot imagine that there is no literary elements in my class. I majored in English literature, and literature is all that $l$ am good at. Now I am asked to teach something pertinent to civil engineering, it is really hard to believe. Can you imagine a teacher who has never learned anything about engineering can teach this course well? Each time I went to my class, I felt I am a fraud and I still feel the same. I do not even understand the basic concepts; you know, one need to learn something in a new field for a period of time, say, a few years, before disciplinary knowledge can be really understood.

The above excerpt shows that P1 was defending herself by highlighting her academic background in literature and the long time needed to become expert in a new disciplinary. P2 also mentioned her little knowledge in the discipline, but she presented the cause of her unwillingness to change directly and unreservedly:

I know little about that discipline. I came from a poor family in the northern part of this province and my family never offer me an opportunity to learn anything about it. You know, to step into that field may cost a family a lot of money. My little knowledge in that discipline makes me unconfident in the ESP course. Any question from the students can make me foxed. Sometimes I even feel that the students have contempt for me. Maybe it is not true, but I just feel that way. English literature is all that I know, which makes me very depressed in ESP classes. So I just explain some terminologies and translate the text sentence by sentence. That's all that I can do.

A close examination of P1's and P2's stance can bring a clearer picture: teachers' learning experiences in literature is one important source of teacher's agency in the process of implementing the national and institutional language education policy, either as an excuse for teachers' illegitimacy, or as an indicator of their incompetence.

\section{Teachers' views on the nature of language learning}


Another cause of teachers' agency in the ESP context is their ideology on the nature of language learning. In China, there is a protracted debate over the property of English learning: some believe foreign language is "instrumental", so it is important to implement ESP reform to help students acquire disciplinary knowledge via English (Cai, 2017b); others insist the learning of a language be essentially "humanistic" because one language is the representation of one specific culture, so cultivating humanistic competence is the kernel of English courses (Feng, 2019). The two different voices permeate both college English (basically for non-English majors) and English as a major. Interview data in this research indicates that most teachers hold a "humanistic" view of foreign language learning, partly because their own learning experiences as an English major were "humanistic". It is hard for them to accept instrumental rationality as the purpose or essence of language learning. P4 directly pointed out:

Language is part of culture. You cannot believe that ESP courses may help students master the cultural value of the language. For me, language learning without a command or an awareness of culture is of no "soul". It is pathetic if all students learn English in this way. So in my ESP class I still went to the cultural part when I explained a new word, though it may cost a lot of time and it is not so relevant to the contents in the ESP textbooks.

The above remarks show that teachers' views on the nature of language learning cannot be simply changed just because of the reform context or administrative requirements. Their views permeate all their teaching practice and are reflected in the students' learning experiences. One student in P4's class said:

It was rather strange, you know, you were attending an ESP class, but you got a lot of information on English culture. Sometimes I wondered if I went into a general English class.

\section{Teachers' profound distrust of the efficacy of ESP courses}

Teachers showed profound distrust of the effectiveness of ESP courses, which is another reason why they exercised agency. According to the interview data, many teachers expressed their worries of ESP students' language competence. P3 problematized the rationale of ESP courses by focusing on students' language proficiency when they first went into the ESP class:

I have to say, on average, students' language skills were poor. I gave them a comprehensive test in the first ESP class; basically it was a test of general English as there were just a few terminologies included. To my surprise, most of them gave a bad performance in the test, although they all passed CET 4 (College English Test Band 4, one national English test for non-English majors in Chinese colleges or universities). My question was then, would they be able to learn ESP courses since their general English competence was not good enough?

Teachers believed it would be really difficult for students to join the ESP courses if their language skills do not meet the requirements. Basically disciplinary materials in English are more difficult to understand as there are more complex sentence structures, more terminologies, and embedded disciplinary principles or knowledge. With a consideration of the actual circumstance, P1, P3 and P5 mentioned that they usually started ESP courses with several classes which were more like general English. But they also admitted that it was impossible to improve students' language skills in a short time. As for the students, teachers' appropriation of the ESP policy was more like "escape":

Since it was an ESP course, why did they start with general English? I think they did not get prepared (for the ESP class).

Teacher agency exercised in this way might cause students' misunderstanding or misinterpretation (which is also revealed in the previous section) and affect the teacher-student relationship in the context of ESP curriculum reform.

4. Teachers' perception of students' unsatisfactory explicit performance

Teachers' "good" intention of starting an ESP course with general English or injecting culture of English-speaking countries into the course has another consequence: students refused to cooperate or behave actively in class, which in turn, misled the teachers. From teachers' perspective, the students' unsatisfactory explicit performance just proved again that it was necessary to make some changes or adjustments to the top-down ESP policy. P3 believed that her choice was right:

According to my observation, the students were unable to express their understandings on disciplinary knowledge. Sometimes I just asked them a simple question, but there was no response. I knew that their lack of English proficiency is an obstacle to their expressions. And I also knew I needed to adjust my expectations and the contents I would teach in class.

P3 assured herself in her appropriation of the ESP policy from her on-the-spot perspective. The message she got was that the students were silent in class, but she misinterpreted the message as students' inability to express. The gap between what she saw and what the facts really were cannot be filled because she exerted her agency directly by making adjustments to the ESP curriculum without conducting a survey to fully understand the students' real needs.

P3's perception was only based on her observations in the classroom, but the interviews with students in this research unveiled something different. As is mentioned, students' explicit performances in class were just representation of their silent resistance against their teachers' agency (i.e., the teachers' adjustments and appropriation of the national and institutional ESP policy).

One more thing that needs to mention is that P5, as a director of the college English teaching department, once got students' feedback from a teacher-student informal meeting in a mid-term teaching inspection. In that meeting, one student told her true feelings of the ESP classes and several others chimed in. In an interview, a student who attended that meeting told the researcher that he remembered the director (P5) made the following remarks — "yes, we need 
make some changes", and took some notes in his notebook. However, it seemed that the "change" did not happen, even in P5's ESP classes.

\section{DISCUSSION}

Teacher agency is usually understood as a means by which teachers can negotiate with power and mediate the policy and teaching practice. It can help policy actors "promote further action and lead to higher and more successful levels of interaction" (van Lier, 2004, p. 95). In other words, agency is perceived as a factor that plays a positive role in language teaching. The negative side of teacher agency in the language education policy change has not been fully explored and elaborated. From results of the current research, one can easily notice that teacher agency in the context of educational reform may turn out to be a defense of teachers' unwillingness to change, which is caused by their confined academic background, their constrained understanding of language education, their bias against the so-called instrumental rationality of ESP courses and their inaccurate perception of students' academic performance. It should be noted that teacher agency exercised in the implementation of the ESP policy needs to be evaluated based on students' needs. The analysis of students' discourses reveals that most of the students show very strong needs for "real" ESP courses, but their voices cannot be heard by the teachers because they chose to remain silent. In this sense, teacher agency exerted in the context of ESP reform cannot be regarded as positive resistance to power or hierarchy; instead, it should be perceived as an evasion of responsivities and accountabilities, the manifestation of human obstinacy, and the unwillingness or inability to understand students' hidden agenda.

As is noted, the negative side of teacher agency is largely unexplored in previous literature, and it is the lacuna that the current study seeks to address. Xu and Long (2020) indicate that further explorations need to be made to ascertain the factors pertinent to agency. The current study explores this issue by conducting a detailed analysis of the causes of teacher agency in the context of ESP reform and focusing on the negative effects of agency. However, it should be admitted that the causes of the teacher agency may be diverse and changeable as the contexts of other language education policy changes can be rather different from that of this study. Therefore, follow-up studies may confirm the factors revealed in this research, or it is probable to discover more factors in other specific contexts.

\section{IMPLICATIONS AND CONCLUSIONS}

This research shows that teachers' views on the nature of language learning and their profound distrust of the efficacy of ESP courses are part of the reason why they interpret the new ESP policy rather differently from the institution. Therefore, it is a necessity to create spaces for negotiating and adjusting the national policy at the instructional level to "empower and facilitate teachers to claim and exercise their agency"(Liu, Wang, \& Zhao, 2020). Claiming or exercising agency does not mean renunciation of the reform initiative; rather it gives teachers opportunities to express their stance and concern, which actually creates a space for the explanation and interpretation of the policy. It is rather important to respond to teachers' worries before implementation by offering convincing and feasible plans. Debates in that space can reveal the difficulties in implementing the policy and ideas to make the reform possible might emerge by a rigorous and cautious design of the implementation steps. Teachers' views might not be changed completely; however, a process of negotiation can at least provide a clearer picture of the course of action and be seen as a symbol of future adjustments if the policy is encountered with difficulties.

The negative side of the exerted teacher agency identified in this research is also the result of teachers' lack of competence in certain disciplines and their failure to know students' real needs in the context of ESP reform. It is then argued that offering effective ESP teacher education programs as affordances to elevate the teachers' competency and pedagogy might be a way conducive to the mediation of their agency. On the other hand, instead of making teachers perceive or analyze their students' needs, which possibly turns out to be untrustworthy (as is proved above), the college of foreign studies, or the English teaching department can help teachers make need analysis by collecting data from surveys conducted anonymously at the institutional level. Students' real needs then are more likely to serve both as pressure and impetus for teachers to undertake their responsibility, and hence, bring positive changes in their agency.

A conclusion can be made that efforts at the institutional level are indispensable in the context of a language education policy and important to the mitigation of the negative effects of teacher agency. The efforts can either be creating a space for negotiation, debate, interpretation or appropriation of the policy, or be providing affordances for teachers to meliorate their competency and pedagogy in the reform context. An institution, instead of being an authoritative entity or an "administrator" that holds power, can also act simply as a helper which for instance may conduct surveys for teachers, or as a bridge between teachers and students. Teacher agency is a complex issue, which has a positive side and a negative side in the context of educational reform. Institutions are an undeniable factor to the shift of teacher agency (from negative to positive) and hence the enactment of a new language education policy.

\section{ACKNOWLEDGMENTS}

The author wishes to thank the participants for their assistance in this research. 


\section{REFERENCES}

[1] Cai, J. (2017a). Review of Chinese tertiary English education: failure and lessons. Journal of Northeast Normal University (Philosophy and Social Sciences) 5, 1-7. doi:10.16164/j.cnki.22-1062/c.2017.05.001.

[2] Cai, J. (2017b). On instrumentality and renwen of foreign language teaching from the perspective of language properties. Journal of Northeast Normal University (Philosophy and Social Sciences) 2, 1-6.

[3] Feng, Y. (2019). Humanistic implications of the English studies in the New Era. Foreign Languages in China, 16. 4, 16-21.

[4] Johnson, D. C. (2013). Language Policy. New York: Palgrave Macmillan.

[5] Kayi-Aydar, H. (2015). Teacher agency, positioning, and English language learners: Voices of pre-service classroom teachers. Teaching \& Teacher Education, 45, 94-103. doi:10.1016/j.tate.2014.09.009.

[6] Liu, Y., Wang, H., \& Zhao, R. (2020). Teacher agency and spaces in changes of English language education policy. Current Issues in Language Planning, 21. 5, 548-566. doi:10.1080/14664208.2020.1791532.

[7] Van Lier, L. (2004). The Ecology and Semiotics of Language Learning: A Sociocultural Perspective. New York: Kluwer Academic Publishers.

[8] Xu, J., \& Long, Z. (2020). Reviewing studies of agency in foreign language teaching and learning. Journal of PLA University of Foreign Languages, 43. 5, 93-100+160.

Shiping Deng was born in Qingdao, Shandong Province in 1986. He received his master degree in Nanjing Forestry University, China in 2011.

$\mathrm{He}$ is currently a lecturer, and a Ph. D candidate in the Institute of Linguistics at Shanghai International Studies University, China. His research Interest: applied linguistics, language policy and language planning. 